\title{
A fatigue limit diagram for plastic rail clips
}

\author{
S. Tamagawa, H. Kataoka \& T. Deshimaru \\ Department of Track Structures and Components, \\ Railway Technical Research Institute, Japan
}

\begin{abstract}
The purpose of this study is to develop a fatigue limit diagram for plastic rail clips. Firstly, a new fatigue limit diagram was formularized based on the mechanical properties of material and its fatigue limit under repeated load. The diagram is represented by the relationship between the mean strain and the strain amplitude. Secondly, the material of the clip was tested to obtain the accurate values of the fundamental properties that constitute the diagram. Finally, fatigue tests were carried out and the fatigue limit diagram was compared with the test results in order to check the validity of the diagram. As a result, it was concluded that the new fatigue limit diagram is available for estimating the fatigue strength of plastic rail clips.

Keywords: rail clip, fatigue limit diagram, plastic deformation, fatigue strength, tensile test, fatigue test.
\end{abstract}

\section{Introduction}

In Japan, rail clips are designed so as to comply with the fatigue limit diagram (Tadashi et al. [1]). The diagram is represented by the relationship between the mean stress and the stress amplitude and is determined depending on the materials of each clip. The diagram can be used in general on the condition that the stress of rail clips under designed load is within their yield strength. However, some cases have been reported that "wire-shaped" rail clips, widely used in Japan currently, show plastic deformation during the process of fastening and in service (e.g. Yuki [2]). The fatigue strength of these clips cannot be estimated adequately because the conventional fatigue limit diagram cannot be applied to them.

Based on the above background, the authors developed an evaluation method for the wire-shaped plastic rail clips by use of a new fatigue limit diagram. 
Firstly, the new fatigue limit diagram was formularized based on the mechanical properties of material and its fatigue limit under repeated load. The diagram was represented by the relationship between the mean strain and the strain amplitude. Secondly, the material of the clip was tested to obtain the accurate values of the fundamental properties that constitute the diagram. Finally, fatigue tests were carried out and the fatigue limit diagram was compared with the test results in order to check the validity of the diagram.

\section{Fatigue limit diagram}

Figure 1 shows the conventional fatigue limit diagram named Goodman's diagram. Each line of the diagram is expressed in the following equations.

Fatigue limit

$$
y=\sigma_{N 10^{7}}-\frac{\sigma_{N 10^{7}}}{\sigma_{T}} x
$$

Fatigue strength $(n<7)$

Elastic limit

$0.2 \%$ Proof stress

$$
y=\sigma_{N 10^{n}}-\frac{\sigma_{N 10^{n}}}{\sigma_{T}} x
$$$$
y=\sigma_{Y}-x
$$$$
y=\sigma_{0.2}-x
$$

where, $x$ is the mean stress; $y$, the stress amplitude; $\sigma_{T}$, the true stress of fracture; $\sigma_{Y}$, the elastic limit; $\sigma_{0.2}$, the $0.2 \%$ proof stress; $\sigma_{N 10}{ }^{7}$, the fatigue limit; and $\sigma_{N 10}{ }^{n}$, the fatigue strength at $n$ cycles. The diagram shown above has been established for the evaluation of elastic materials and it cannot be applied to the plastic one. Therefore, the authors improved the diagram in terms of strain based on the elastic-plastic mechanical properties of material and its fatigue limit under repeated load.

The stress-strain curve is obtained as shown in eqn. (5) from a simple tensile test on the piece of rail clips.

$$
\varepsilon=f(\sigma, \alpha, \beta, \gamma, \cdots)
$$

where, $\varepsilon$ is the strain; $\sigma$, the stress; and $\alpha, \beta, \gamma \ldots$, the mechanical properties of material. The relationship between the stress and the strain of the material under cyclic load (see fig. 2) can be described as follows:

$$
\begin{gathered}
X+Y=f(x+y, \alpha, \beta, \gamma, \cdots), \\
Y=y / E .
\end{gathered}
$$

where, $X$ is the mean strain; $Y$, the strain amplitude; and $E$, Young's modulus. Equation (6) shows that the sum of the mean strain and the strain amplitude coincides with the value, which is on the stress-strain curve. Equation (7) expresses that gradient between stress and strain under cyclic load coincides with the Young's modulus. Equations (6) and (7) hold on the condition that the material shows plastic deformation under maximum load and shows elastic deformation under cyclic load. Thus, this study deals with high cycle fatigue problem excluding the case where rail clips show progressive plastic deformation by cyclic load and break due to low cycle fatigue. The substitution 


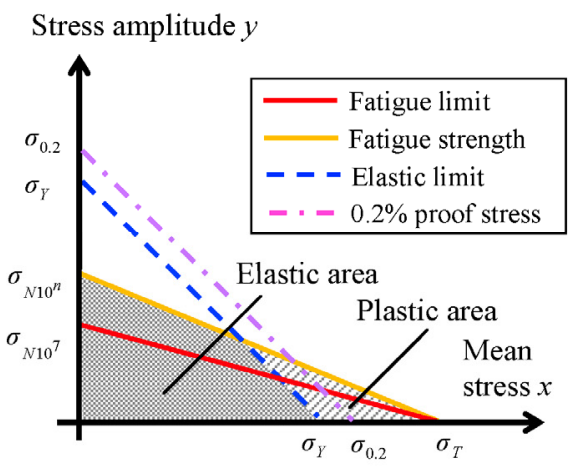

Figure 1: Goodman's diagram.

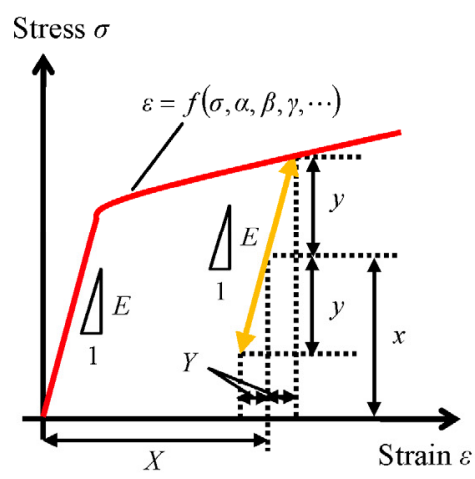

Figure 2: Relationship between stress and strain under loading.

of eqns. (1)-(4) into eqns (6) and (7) leads to the new fatigue diagram for plastic rail clips in terms of the mean strain $X$ and the strain amplitude $Y$. For spring steel materials, the stress-strain curve can be expressed in the following equation.

$$
\varepsilon=\frac{\sigma}{E}+0.002\left(\frac{\sigma}{\sigma_{0.2}}\right)^{m}
$$

where, $m$ is the hardening coefficient. Equation (8) is based on the RambergOsgood curve (Ramberg and Osgood [3]) which is often used for steel materials. $m$ is determined so as to pass a given point (Rasmussen [4]). In this study, $m$ is determined so as to pass the tensile strength $\left(\sigma_{B}, \varepsilon_{B}\right)$. In such cases, the stress-strain curve by eqn. (8) is not necessarily in good agreement with the test results beyond the tensile strength. However, even in such cases, eqn. (8) can be used sufficiently because the measured maximum strain of rail clips is about 10000 to $15000 \mu$ and is lower than the tensile strength strain. When eqn. (8) is substituted into eqn. (5), eqns. (1)-(7) can be rearranged to give the fatigue limit diagram as follows. In addition, a limit line named 'Tensile limit' is defined in eqn. (13). The allowable range of the diagram is the area under the line of eqn. (13).

Fatigue limit

$$
X=\frac{\sigma_{T}}{E}-\frac{\sigma_{T}}{\sigma_{N 10^{7}}} Y+0.002\left[\left\{\sigma_{T}+\left(1-\frac{\sigma_{T}}{\sigma_{N 10^{7}}}\right) E Y\right\} / \sigma_{0.2}\right]^{m}
$$

Fatigue strength $(n<7) \quad X=\frac{\sigma_{T}}{E}-\frac{\sigma_{T}}{\sigma_{N 10^{n}}} Y+0.002\left[\left\{\sigma_{T}+\left(1-\frac{\sigma_{T}}{\sigma_{N 10^{n}}}\right) E Y\right\} / \sigma_{0.2}\right]^{m}$

Elastic limit

$$
X=\frac{\sigma_{Y}}{E}+0.002\left(\frac{\sigma_{Y}}{\sigma_{0.2}}\right)^{m}-Y
$$


$0.2 \%$ Proof stress

Tensile limit

$$
\begin{gathered}
X=\frac{\sigma_{0.2}}{E}+0.002-Y \\
X=\frac{\sigma_{B}}{E}+0.002\left(\frac{\sigma_{B}}{\sigma_{0.2}}\right)^{m}-Y
\end{gathered}
$$

\section{Material tests and mechanical properties}

The material of the clip was tested to obtain the accurate values of the fundamental properties that constitute the diagram formularized in the prior section.

\subsection{Rail clip}

Rail clips type FC1503 (fig. 3), which have been produced by Pandrol UK Ltd, were tested to obtain the mechanical properties. The clips were produced using black bar and were austenitised using gas heating. In the previous study, it was reported that the clip shows plastic deformation during the process of fastening and under loading (e.g. Yuki [2]).

\subsection{Tensile test}

A simple tensile test on four pieces of the clips was carried out (fig. 4). The test was based on Japanese Industrial Standards (JIS Z2214). As a result, Table 1 shows the mechanical properties and fig. 5 shows the relationship between the stress and the strain. The results of each piece (Nos 1-4) show a good agreement with each other. Young's modulus was about $181-197 \mathrm{kN} / \mathrm{mm}^{2}, 0.2$ proof stress was about $1329-1446 \mathrm{~N} / \mathrm{mm}^{2}$, the tensile strength was about $1457-1577 \mathrm{~N} / \mathrm{mm}^{2}$, and the true stress of fracture was about $1881-1961 \mathrm{~N} / \mathrm{mm}^{2}$. As shown in table 2, hardening coefficient $m$ in eqn. (8) was calculated on the basis of the test results. In fig. 6, stress-strain curve calculated by eqn. (8) is compared with the test result. The test result was in good agreement with eqn. (8).

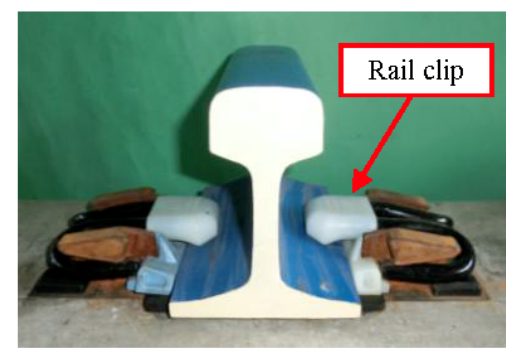

Figure 3: Rail clip (FC1503).

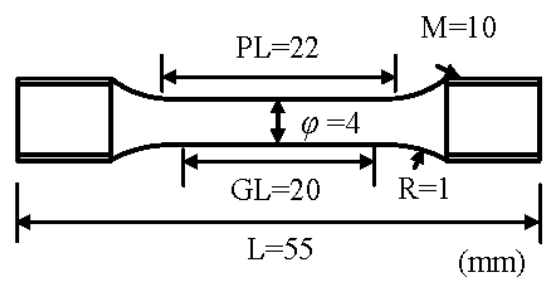

Figure 4: Tensile test piece. 
Table 1: Mechanical properties.

\begin{tabular}{ccccccc}
\hline & $\begin{array}{c}E \\
\left(\mathrm{kN} / \mathrm{mm}^{2}\right)\end{array}$ & $\begin{array}{c}\sigma_{0.2} \\
\left(\mathrm{~N} / \mathrm{mm}^{2}\right)\end{array}$ & $\begin{array}{c}\sigma_{B} \\
\left(\mathrm{~N} / \mathrm{mm}^{2}\right)\end{array}$ & $\begin{array}{c}\sigma_{T} \\
\left(\mathrm{~N} / \mathrm{mm}^{2}\right)\end{array}$ & $\begin{array}{c}\varepsilon_{0.2} \\
(\%)\end{array}$ & $\begin{array}{c}\varepsilon_{B} \\
(\%)\end{array}$ \\
\hline \hline No. 1 & 190.1 & 1388 & 1514 & 1961 & 0.93 & 5.35 \\
\hline No. 2 & 196.6 & 1446 & 1577 & 1906 & 0.94 & 5.48 \\
\hline No. 3 & 197.1 & 1345 & 1473 & 1876 & 0.88 & 5.85 \\
\hline No. 4 & 181.1 & 1329 & 1457 & 1881 & 0.93 & 6.20 \\
\hline Average & 191.2 & 1377 & 1505 & 1906 & 0.92 & 5.72 \\
\hline
\end{tabular}

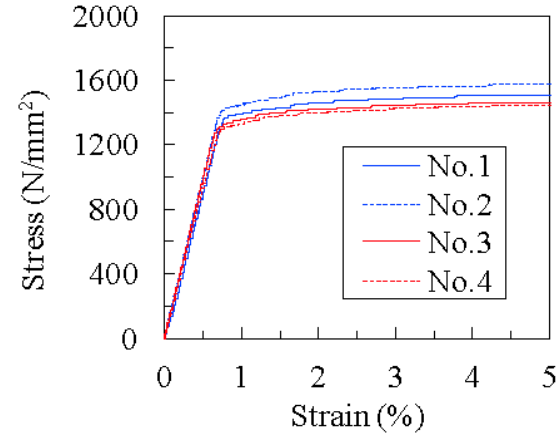

Figure 5: Relationship between stress and strain.

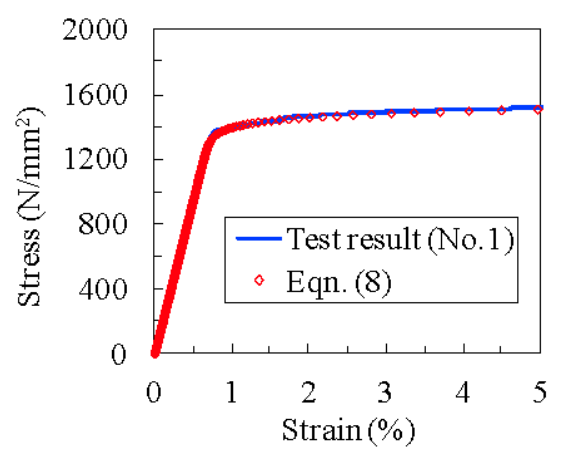

Figure 6: Test results and eqn. (8).

Table 2: Hardening of coefficient $m$.

\begin{tabular}{cccccc}
\hline & No. 1 & No. 2 & No. 3 & No. 4 & Average \\
\hline \hline$m$ & 36.1 & 36.2 & 35.6 & 35.6 & 35.9 \\
\hline
\end{tabular}

\subsection{Fatigue test}

Fatigue tests under repeated load were carried out in order to obtain the elastic fatigue strength of the clip. The tests were based on 14 S-N method (JSME [5]). The machine was set up as in fig. 7, so that the strain can be measured in the arch of the strain gauged clip (fig. 8). A variety of dynamic loads were superimposed on the applied static load $4.0 \mathrm{kN}$. For the purposes of the tests, the maximum number of the cycles was ten million.

As a result, fig. 9 shows the relationship between the stress amplitude and the number of cycles together with the S-N curves (failure probability: 10, 50, 90\%) estimated by the staircase method (JSME [5]). As shown in fig. 10, the fatigue strength of the clip under reversed load was estimated on the basis of the tensile test results and the fatigue tests results. Table 3 shows the fatigue strength of the clip under reversed load. The fatigue limit and the fatigue strength at $10^{6}$ cycles were about $400 \mathrm{~N} / \mathrm{mm}^{2}$ and the fatigue strength at $10^{5}$ cycles was about $500 \mathrm{~N} / \mathrm{mm}^{2}$ under reversed load. 


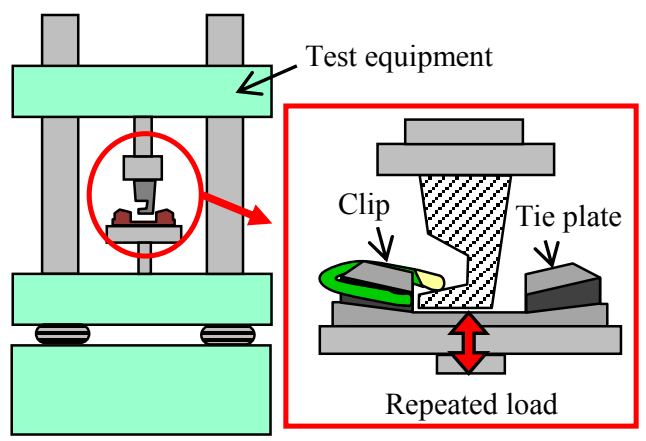

Figure 7: Experimental set up.

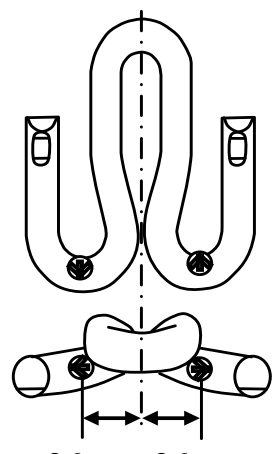

$26 \mathrm{~mm} 26 \mathrm{~mm}$

Figure 8: Strain gauged clip.
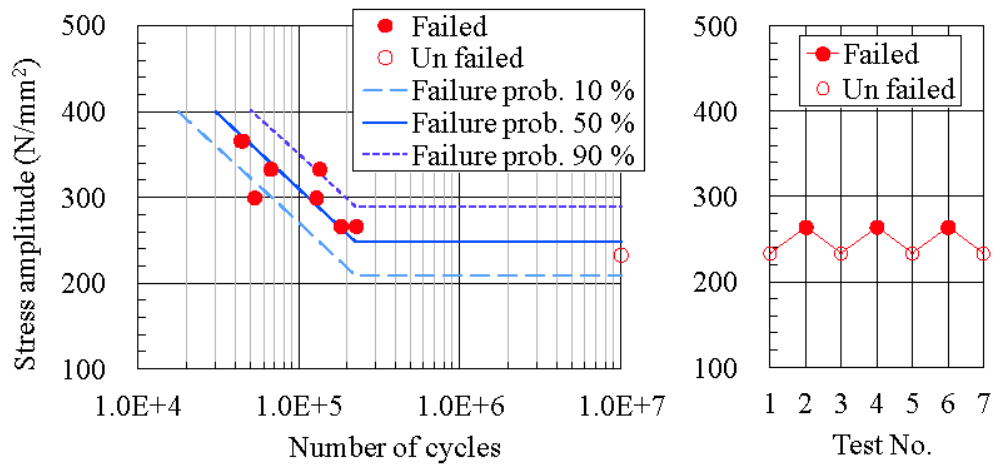

Figure 9: $\mathrm{S}-\mathrm{N}$ curves (14 S-N method, static load: $4.0 \mathrm{kN}$ ).
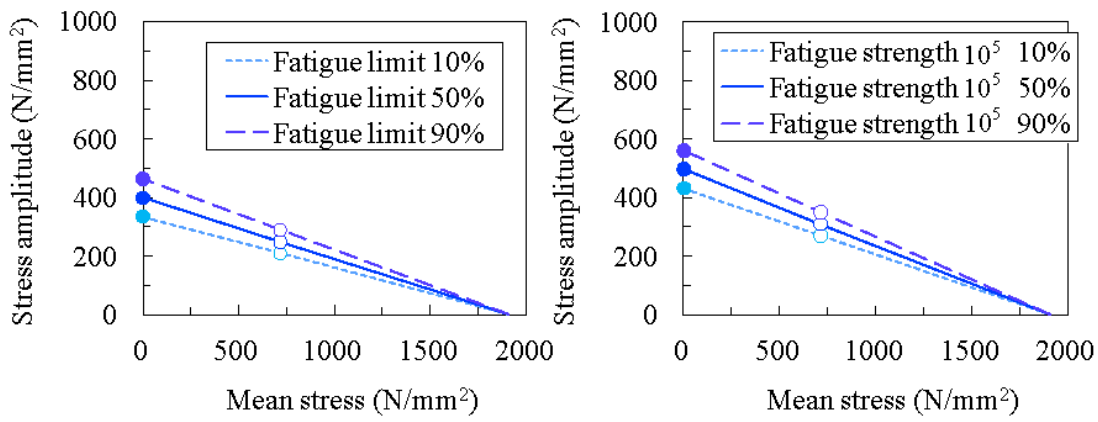

Figure 10: Estimation of fatigue limit and strength under reversed load. 
Table 3: $\quad$ Fatigue strength under reversed load.

\begin{tabular}{cccc}
\hline $\begin{array}{c}\text { Failure } \\
\text { Probability }\end{array}$ & $\begin{array}{c}\text { Fatigue limit } \\
\sigma_{N 10}{ }^{7}\end{array}$ & $\begin{array}{c}\text { Fatigue } \\
\text { strength } \\
\sigma_{N 10}\end{array}$ & $\begin{array}{c}\text { Fatigue } \\
\text { strength } \\
\sigma_{N 10}\end{array}$ \\
\hline \hline $10 \%$ & 334 & 334 & 432 \\
\hline $50 \%$ & 398 & 398 & 497 \\
\hline $90 \%$ & 463 & 463 & 561 \\
\hline
\end{tabular}

\section{Fatigue test and the diagram}

\subsection{Fatigue limit diagram based on material tests}

In order to determine the fatigue limit diagram for plastic clips, eqns. (9)-(13) were calculated using each value obtained from material tests. Figure 11 shows the fatigue limit diagram and table 4 shows the fundamental properties that constitute the diagram. Each line shown in fig. 11 indicates that there is a $50 \%$ chance of failure of the clip.

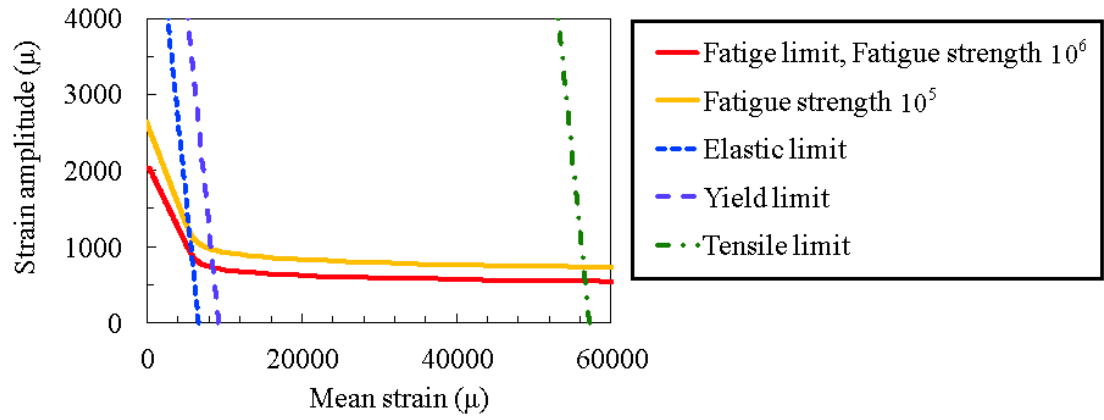

Figure 11: Fatigue limit diagram based on material tests.

Table 4: Fundamental properties.

\begin{tabular}{ccccccccc}
\hline$\sigma_{T}$ & $\sigma_{0.2}$ & $\sigma_{Y}$ & $\sigma_{B}$ & $E$ & $m$ & $\sigma_{N 10}{ }^{7}$ & $\sigma_{N 10}{ }^{6}$ & $\sigma_{N 10}{ }^{5}$ \\
\hline \hline 1906 & 1377 & 1250 & 1505 & 191.2 & 35.9 & 398 & 398 & 497 \\
\hline
\end{tabular}




\subsection{Fatigue tests and the validity of the diagram}

A number of fatigue tests on the clip were carried out and the fatigue limit diagram was compared with the test results in order to check its validity. The machine was set up as in fig. 12. The clips were subjected to the vertical load under various conditions due to the varying dynamic load and static load. Maximum number of the cycles was one million. Strains of clips were measured by strain gauges affixed at the arch of the clip and the measurements were recorded in terms of principal strain. Strains were measured in the range of $3000 \mu$ to $30000 \mu$.

Test results are plotted on the diagram as shown in fig. 13. In addition, table 5 shows the test data in detail. In fig. 13, "Un failed" means clips which attained one million cycles and "Failed" means clips which were broken before one million cycles. As the mean strain increases, the boundary line between "Failed" and "Un failed" of the test results tends to fall and this tendency agrees with the diagram. In the elastic area, the fatigue strength of the test results, expressed in terms of strain amplitude, decreases with the increases in the mean strain and this finding agrees with the fatigue strength line (one million cycles) of the diagram. On the other hand, in the plastic area, both the test results and the fatigue strength line of the diagram show approximately the same behaviour, although
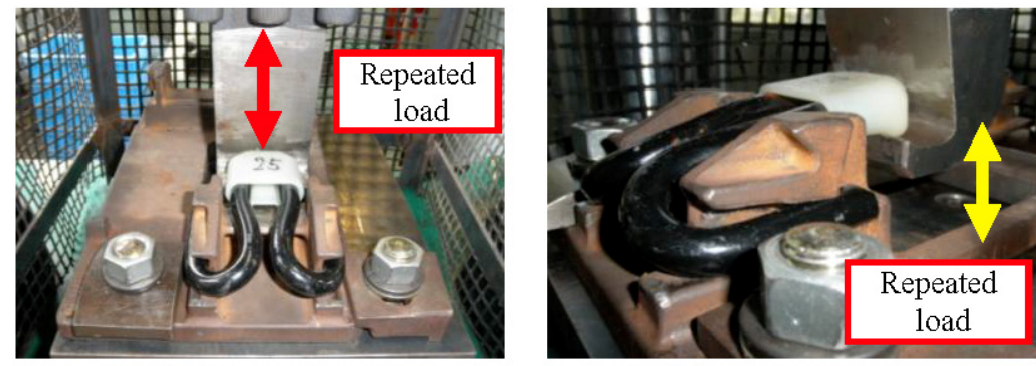

Figure 12: Experimental set up.
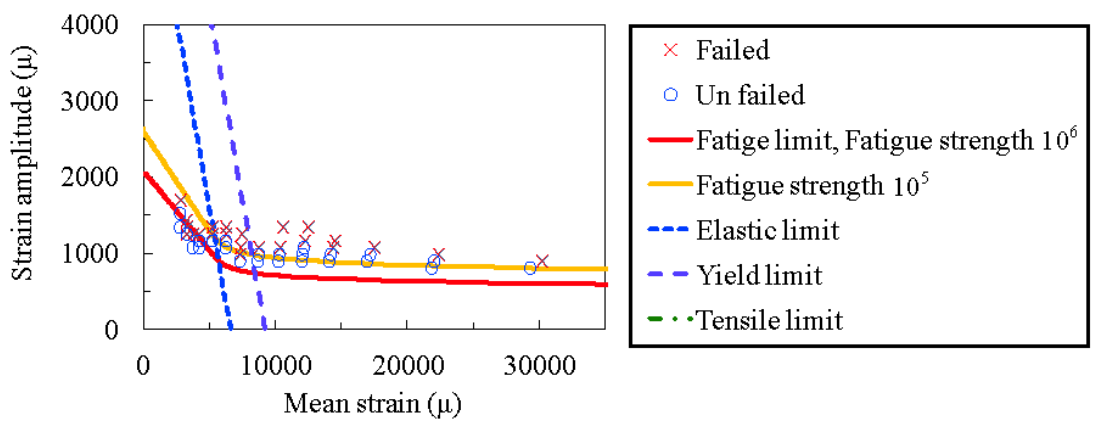

Figure 13: Fatigue limit diagram and test results. 
Table 5: Fatigue test results.

\begin{tabular}{|c|c|c|c|c|c|c|c|c|c|c|c|}
\hline \multirow{2}{*}{ No. } & \multicolumn{2}{|c|}{ Strain $(\mu)$} & \multirow{2}{*}{$\begin{array}{l}\text { No. of } \\
\text { cycles }\end{array}$} & \multirow{2}{*}{ No. } & \multicolumn{2}{|c|}{ Strain $(\mu)$} & \multirow{2}{*}{$\begin{array}{l}\text { No. of } \\
\text { cycles }\end{array}$} & \multirow{2}{*}{ No. } & \multicolumn{2}{|c|}{ Strain $(\mu)$} & \multirow{2}{*}{$\begin{array}{l}\text { No. of } \\
\text { cycles }\end{array}$} \\
\hline & $X$ & Y & & & $X$ & Y & & & $X$ & Y & \\
\hline$\overline{11}$ & 2685 & 13339 & $10^{6}$ & 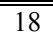 & $\overline{c 5152}$ & 1339 & 208,326 & 35 & $\begin{array}{l}11,960 \\
\end{array}$ & $\overline{c 982}$ & $1 \bar{c}^{6}$ \\
\hline 2 & 2698 & 1518 & $10^{6}$ & 19 & 6154 & 1071 & $10^{6}$ & 36 & 12,068 & 1071 & $10^{6}$ \\
\hline 3 & 2751 & 1696 & 121,502 & 20 & 6152 & 1160 & $10^{6}$ & 37 & 12,179 & 1160 & 162,353 \\
\hline 4 & 3197 & 1250 & $10^{6}$ & 21 & 6209 & 1250 & 331,806 & 38 & 12,406 & 1339 & 131,092 \\
\hline 5 & 3197 & 1250 & 228,259 & 22 & 6206 & 1339 & 137,339 & 39 & 13,971 & 893 & $10^{6}$ \\
\hline 6 & 3222 & 1339 & 133,097 & 23 & 7237 & 893 & $10^{6}$ & 40 & 14,097 & 982 & $10^{6}$ \\
\hline 7 & 3209 & 1428 & 149,616 & 24 & 7248 & 982 & 423,105 & 41 & 14,301 & 1071 & 377,913 \\
\hline 8 & 3644 & 1071 & $10^{6}$ & 25 & 7312 & 1071 & 319,111 & 42 & 14,432 & 1160 & 215,205 \\
\hline 9 & 3696 & 1250 & 161,804 & 26 & 7396 & 1250 & 182,543 & 43 & 16,836 & 893 & $10^{6}$ \\
\hline 10 & 4146 & 1071 & $10^{6}$ & 27 & 8572 & 893 & $10^{6}$ & 44 & 17,088 & 982 & $10^{6}$ \\
\hline 11 & 4146 & 1071 & $10^{6}$ & 28 & 8653 & 982 & $10^{6}$ & 45 & 17,435 & 1071 & 696,870 \\
\hline 12 & 4134 & 1160 & $10^{6}$ & 29 & 8676 & 1071 & 598,080 & 46 & 21,737 & 803 & $10^{6}$ \\
\hline 13 & 4134 & 1160 & $10^{6}$ & 30 & 10,151 & 893 & $10^{6}$ & 47 & 21,934 & 893 & $10^{6}$ \\
\hline 14 & 4161 & 1250 & 136,098 & 31 & 10,185 & 982 & $10^{6}$ & 48 & 22,274 & 982 & 490,709 \\
\hline 15 & 4161 & 1250 & 307,266 & 32 & 10,278 & 1071 & 357,183 & 49 & 29,197 & 803 & $10^{6}$ \\
\hline 16 & 5129 & 1160 & $10^{6}$ & 33 & 10,509 & 1339 & 161,538 & 50 & 30,107 & 893 & 625,174 \\
\hline 17 & 5159 & 1250 & 267,437 & 34 & 11,916 & 893 & $10^{6}$ & & & & \\
\hline
\end{tabular}

$X$ : Mean strain; $Y$ : Strain amplitude.

the fatigue strength of the test results is about $400 \mu$ larger than that of the diagram. The difference between the test results and the diagram can be ignored, as a matter of fact, because the difference is small and the fatigue strength is estimated on the safe side.

From the above results, it can be concluded that the new fatigue limit diagram is available for estimating the fatigue strength of plastic rail clips.

\section{Conclusion}

This study examined the fatigue limit diagram for plastic rail clips. The obtained main results are as follows.

(1) A new fatigue limit diagram was formularized based on the elastic-plastic mechanical properties of material and its fatigue limit under repeated load. The diagram was represented by the relationship between the mean strain and the strain amplitude.

(2) A material of the rail clip (FC1503) was tested and the accurate values of the fundamental properties that constitute the diagram were obtained.

(3) A number of fatigue tests on the clip were carried out and the fatigue limit diagram was compared with the test results. As a result, it can be concluded that the diagram is available for estimating the fatigue strength of plastic rail clips. 


\section{References}

[1] Tadashi, D., Takashi, M., Hiroo, K. \& Osamu. W. Laying standards of wire spring clip fastening system in the curved section, RTRI report, Vol. 27, pp. 37-40, 2012.

[2] Yuki, N. A method for simulating stress of round bar rail clips using nonlinear elastic-plastic dynamic explicit FEA, Proc. of the $12^{\text {th }}$ Int. Conf. on Railway Engineering 2013, London, 2013.

[3] Ramberg, W. \& Osgood, W. Determination of stress-strain curves by three parameters, Technical note No. 902, National advisory Committee on Aeronautics, 1941.

[4] Rasmussen, K. Full-range stress-strain curves for strain less steel alloys, The Univ. of Sydney Department of Civil Eng. Austria, Research Report No. R811, 2006.

[5] The Japan Society of Mechanical Engineers (JSME), Standard method of statistical fatigue testing ( $2^{\text {nd }}$ Edition), Maruzen, 1994. 